\title{
The Mechanical Properties of Concrete Prepared with Recycled Aggregates and Crushed Bricks
}

\author{
E. Abuharrira, A. Mustafa, M. Ali ${ }^{1}$ and A. Elwakeel ${ }^{2}$
}

\begin{abstract}
This paper demonstrates the effect of introducing the Crushed Bricks (Brick ships) in the mechanical properties of concrete prepared with recycled aggregates. Four mixes of concrete with target compressive cube strength of $25 \mathrm{MPa}$ were firstly casted using normal aggregate and different percentage of recycled coarse aggregate. Then recycled aggregates were partially replaced by crushed bricks. The development of the cube compressive strength at ages of 7, 14, 28 days and the tensile cylinder strength at 28 days were tested and recorded for all specimens. The results showed that the 28-day strength readings of concrete with recycled aggregate (RCA) varied in the range of \pm 3percentage of those for the Control Mix. However, the decrease in the strength with the increase of the brick ships replacement was up to 20 Present of the Control Mix.
\end{abstract}

Keywords - Crushed Brick, Mechanical Properties Recycled Aggregates,

\section{INTRODUCTION}

Recycling concrete is one of the solutions to the depletion of natural aggregate resources and the pollution caused by construction waste from demolished old buildings. Construction waste amount to a large percent of the total solid waste, landfills and recycling concrete and masonry rubble will save space and the energy required to transport the rubble from the construction site.

The use of recycled aggregate as an 'artificial aggregate' could be a simple and cheap way of obtaining an environmentally friendly sustainable concrete for structural and non structural proposes. Many studies in the properties and uses of recycle concrete had been conducted and show that recycle concrete can be successfully used for low grade applications and secondary structural member such as ground floors and pavements not subjected to high stresses.

\section{II.LITERATURE REVIEW}

Many building and infrastructure project that had been built in the last century are now absolute and in the near future will have to be demolished or replaced with larger structures to cob with rapid increase of population and the expansion of cities vertically and horizontally.

\footnotetext{
${ }^{1}$ Students, Sudan University of Science and Technology, Sudan

${ }^{2}$ Lecturer, Sudan University of Science and Technology, Sudan
}

The rubble resulting from demolishing these structures plus the construction form rejected concrete, breakage; maintenance and over ordering can cause a big strain on the landfills and dumps resulting in over flowing. Recycling some of the concrete form these sources is the best way to achieve the maximum utilization of martial and helps preserving the natural aggregate resources.

The property and use of recycled aggregate for structural or non-structural concrete have been studied extensively and numerous findings have been adopted in demonstration projects and to produce sustainable concrete.

In demolished buildings concrete rubble is mixed with other wastes such as crushed bricks. And the difference in the water absorption and specific weight and other properties will affect the physical and mechanical properties of the concrete and by studying the affect of different percentages of crushed bricks and determining the optimum portions of the blend between recycle aggregate and crushed bricks that allow for a maximum utilization of the available material. Separating brick ships from recycled aggregate is difficult and expensive in practice. Therefore, it is important to study the effect of crushed bricks on the compressive and tensile resistances, workability, compacting and finishing in the resulting new concrete.

The use of recycled fine aggregate is not recommended and can result in reduction of the compressive resistance and handling difficulties may be experienced in conventional plant (eg sticking-up in hoppers). And recycled fine aggregate may contain high level of impurities.

\section{MATERIAL PREPARATION AND TESTING}

\section{1)The mix design and proportions}

One concrete mix was used with the same proportions expect the coarse aggregate in which the natural aggregate was partially replaced with different percentages of recycled aggregate and crushed bricks The mix was designed according to the BS 5328-part 2 and the ST5 mix was selected with a characteristic compressive strength $25 \mathrm{Mpa}$ with normal Portland cement and no additives. And the maximum aggregate size is $20 \mathrm{~mm}$ and the slump between (3-6) $\mathrm{cm}$.

\section{2) Cement}

The cement type used normal Portland cement $42.5 \mathrm{~N}$ was complied with the Sudanese specification 2011 and the European specification EN 196 -1. 


\section{3) Natural aggregate}

The recycled aggregate was obtained from a local supplier and pass through sieves $(20-4.75) \mathrm{mm}$ as determined in the mix design. The aggregate was cleaned and washed and tested.

\section{4) Recycled aggregate}

The recycled aggregate was obtained from old crushed standard compressive test cubes with a design compressive resistance of $25 \mathrm{Mpa}$ and an age between (6-12) month by crushing the cubes manually and passing the aggregate through sieves (20-4.75) $\mathrm{mm}$ to match those of the natural aggregate. The resulting aggregate then cleaned and washed and tested as shown in Fig.1, 2.the recycled aggregate will be treated as the natural aggregate during the testing mixing and casting.
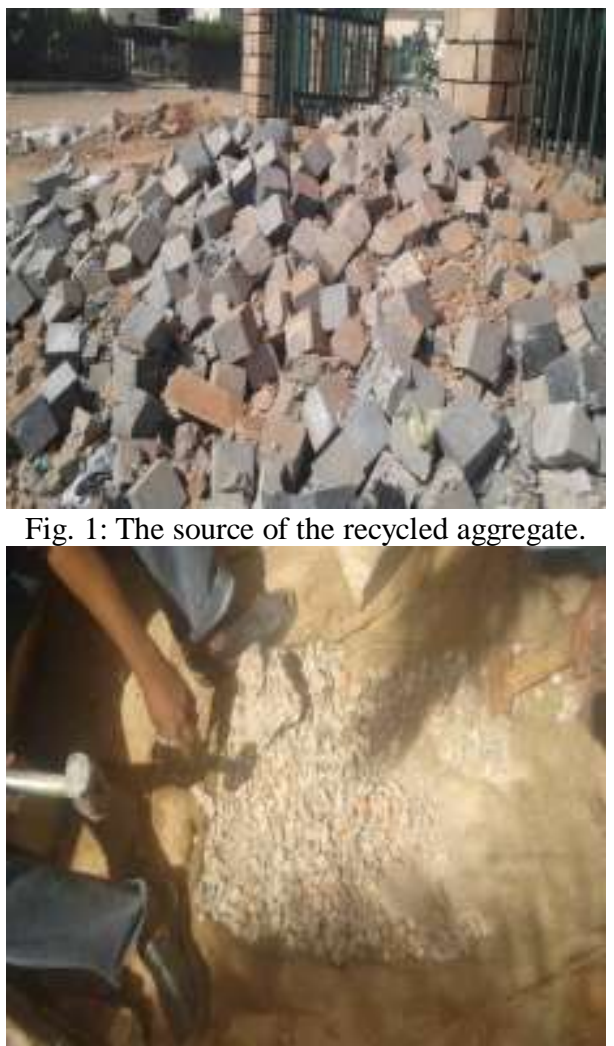

Fig. 2: Manual crushing of the recycled aggregate.

\section{5) Crushed bricks}

The crushed bricks were obtained from demolished masonry wall in the university Fig. 3 about 25 years old and the crushed bricks with the mortar still attach was pass through sieves (204.75) $\mathrm{mm}$ to match those of the natural aggregate. The resulting aggregate then cleaned and washed and tested. The crushed bricks will be treated as the natural aggregate during the testing but before the mixing the aggregate will be pre-wetted because the high water absorption effect on the workability.

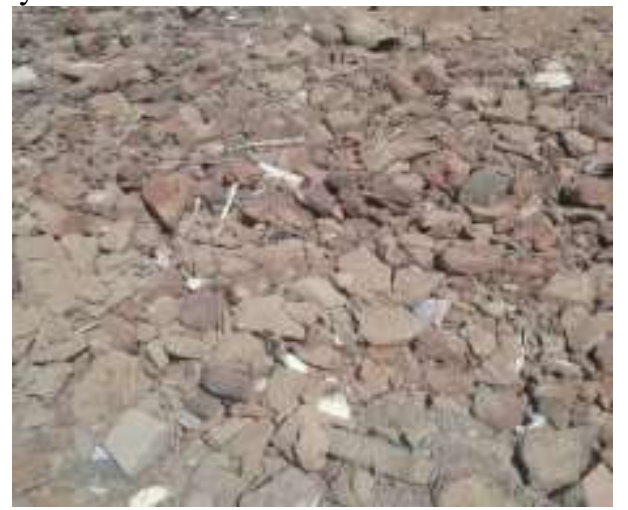

Fig. 3: The source of the crushed bricks

TABLE I: THE AGGREGATE TEST RESULTS

\begin{tabular}{l|cc}
\hline \multicolumn{1}{c|}{ Aggregate } & $\begin{array}{c}\text { Water absorption } \\
(12.5 \mathrm{~mm}), \%\end{array}$ & $\begin{array}{c}\text { Specific weight } \\
(\text { OD })(12.5 \mathrm{~mm}), \\
\mathrm{kg} / \mathrm{m}^{3}\end{array}$ \\
\hline Natural aggregate & 0.50 & 2620 \\
Recycled aggregate & 4.61 & 2450 \\
Crushed bricks & 16.40 & - \\
\hline
\end{tabular}

\begin{tabular}{llllc}
\hline \multicolumn{5}{c}{ TABLE II: THE PERCENTAGES OF COARSE AGGREGATES } \\
\hline MIX & $\begin{array}{l}\text { Natural } \\
\text { aggregate }\end{array}$ & $\begin{array}{l}\text { Recycled } \\
\text { aggregate }\end{array}$ & $\begin{array}{l}\text { Crushed } \\
\text { bricks }\end{array}$ & Remarks \\
& $N \%$ & $R \%$ & $B \%$ & \\
& 100 & - & - & Control mix \\
\hline $\mathrm{A}$ & 90 & 10 & - & Recycled \\
\hline $\mathrm{B}$ & 75 & 25 & - & aggregate \\
$\mathrm{C}$ & 60 & 40 & - & mixes \\
$\mathrm{D}$ & 50 & 40 & 10 & Blend of \\
\hline $\mathrm{E}$ & 50 & 30 & 20 & recycled \\
$\mathrm{F}$ & 50 & 20 & 30 & aggregate \\
$\mathrm{G}$ & 50 & 10 & 40 & and crushed \\
$\mathrm{H}$ & & & & \\
& & & &
\end{tabular}

\begin{tabular}{|c|c|c|c|c|c|c|c|c|}
\hline MIX & $\bar{A}$ & $B$ & $\bar{C}$ & $\bar{D}$ & $E$ & $\bar{F}$ & $G$ & $\bar{H}$ \\
\hline Free water, $\left(\mathrm{kg} / \mathrm{m}^{3}\right)$ & 180 & 180 & 180 & 180 & 180 & 180 & 180 & 180 \\
\hline Fine aggregate, $\left(\mathrm{kg} / \mathrm{m}^{3}\right)$ & 700 & 700 & 700 & 700 & 700 & 700 & 700 & 700 \\
\hline Natural coarse aggregate, $\left(\mathrm{kg} / \mathrm{m}^{3}\right)$ & 1100 & 990 & 825 & 660 & 550 & 550 & 550 & 550 \\
\hline Recycled coarse aggregate, $\left(\mathrm{kg} / \mathrm{m}^{3}\right)$ & _ & 110 & 275 & 440 & 440 & 330 & 220 & 110 \\
\hline Crush bricks coarse aggregate, $\left(\mathrm{kg} / \mathrm{m}^{3}\right)$ & _ & - & - & - & 110 & 220 & 330 & 440 \\
\hline Slump, $(\mathrm{cm})$ & 4.5 & 3.5 & 4.0 & 6.0 & 3.0 & 5.5 & 4.0 & 3.0 \\
\hline Free water/cement ratio & 0.53 & 0.53 & 0.53 & 0.53 & 0.53 & 0.53 & 0.53 & 0.53 \\
\hline Total water/cement ratio & 0.55 & 0.56 & 0.58 & 0.59 & 0.59 & 0.58 & 0.56 & 0.55 \\
\hline
\end{tabular}




\section{CONCRETE TESTING AND RESUlts}

\section{1) The slump test}

The slump test was performed to determine the workability of each of the mixes in relation to the total water to cement ratio according to the BS EN 12350-2 and the results are as shown in Table IV.

\section{2) The compressive resistance}

The compressive resistance is one of the basic and most important mechanical properties and the concrete member design is usually base on the compressive strength. The standard compressive resistance BS 1881-part16 is performed with the standard $150 \times 150 \times 150 \mathrm{~mm}$ cubes tested at the ages 7 , 14 and 28 days to determine the development of the compressive resistance and the characteristic compressive strength.

\section{3) The tensile resistance}

The splitting cylinder indirect tensile resistance is preformed to determine the concrete member resistance to tensile failure and cracks. The test was performed according to BS 1881-part117 to determine the characteristic tensile strength at the age of 28 days.

TABLE IV: COMPRSSIVE AND TENSILE TEST RESULT

\begin{tabular}{c|ccc|c}
\hline & $\begin{array}{c}\text { Compressive } \\
\text { resistance at } \\
7 \text { days }\end{array}$ & $\begin{array}{c}\text { Compressive } \\
\text { resistance at } \\
14 \text { days } \\
(M P a)\end{array}$ & $\begin{array}{c}\text { Compressive } \\
\text { resistance at } \\
28 \text { days } \\
(M P a)\end{array}$ & $\begin{array}{c}\text { Tensile } \\
\text { resistance } \\
\text { at 28 days } \\
(M P a)\end{array}$ \\
\hline A & 28.0 & 30.0 & 34.5 & 2.35 \\
B & 30.0 & 31.5 & 34.5 & 2.90 \\
C & 25.0 & 30.0 & 35.5 & 2.45 \\
D & 28.0 & 30.5 & 35.5 & 2.45 \\
E & 26.0 & 28.0 & 35.5 & 1.80 \\
F & 25.0 & 28.0 & 31.0 & 1.95 \\
G & 23.5 & 28.0 & 29.5 & 1.95 \\
H & 20.0 & 20.5 & 24.0 & 2.05 \\
\hline
\end{tabular}

*Values expressed to the nearest $0.5 \mathrm{MPa}$ for compressive resistance and to the nearest $0.05 \mathrm{MPa}$ for tensile resistance.

\section{DISCUSSION}

\section{1) Workability}

All the slump test results were in the specified range in the mix design which indicates the good workability of the mixes. The mix D containing $40 \%$ recycle aggregate gives a slightly higher workability than the control mix.

The crushed brick has a negative affect on the workability decreasing it by $50 \%$ comparing to the control mix when using $40 \%$ crushed bricks.

\section{2) Compressive resistance}

The result shows that the mixes containing recycled aggregate had a compressive resistance in 28 days higher or equal to the compressive resistance of control mix. With $10 \%$ recycled aggregate the compressive resistance was equal to the compressive resistance of control mix and with $25 \%$ and $40 \%$
It had a higher compressive resistance than the control mix by about $1 \mathrm{MPa}$.

At the age of 7 days the mix containing $10 \%$ recycled aggregate had $7 \%$ higher compressive resistance than the control mix and the mix containing $25 \%$ had $17 \%$ higher compressive resistance than the control mix A. The $40 \%$ recycled aggregate mix had compressive resistance equal to the compressive resistance of control mix as shown in Fig.4.

At the age of 14 days the mix containing $10 \%$ recycled aggregate had $10 \%$ compressive resistance than the control mix and 25\% mix had the same compressive resistance as the control mix. The $40 \%$ recycled aggregate mix had $2 \%$ higher compressive resistance than the control mix as shown in Fig.5.

The recycled aggregate has positive effect on the 28 days compressive resistance the mix containing $10 \%$ recycled aggregate had the same compressive resistance as the control mix and 25\% and 40\% mixes had had $0.03 \%$ higher compressive resistance than the control mix as shown in Fig.6.

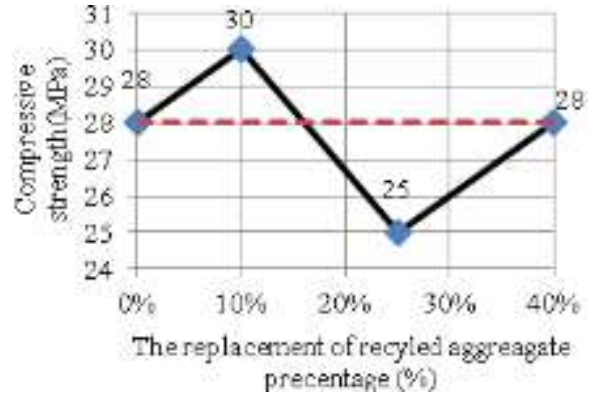

Fig. 4: Compressive resistance of mixes containing recycled aggregate at the age of 7 days.

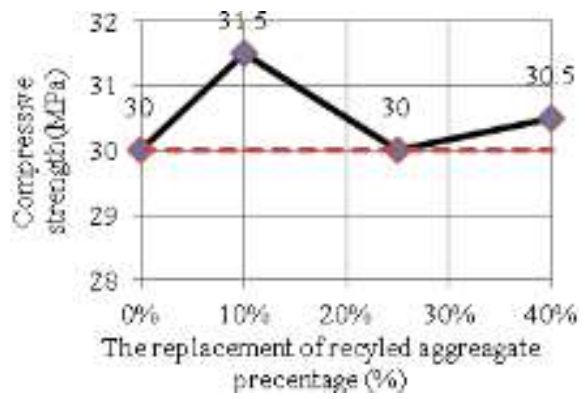

Fig. 5: Compressive resistance of mixes containing recycled aggregate at the age of 14 days.

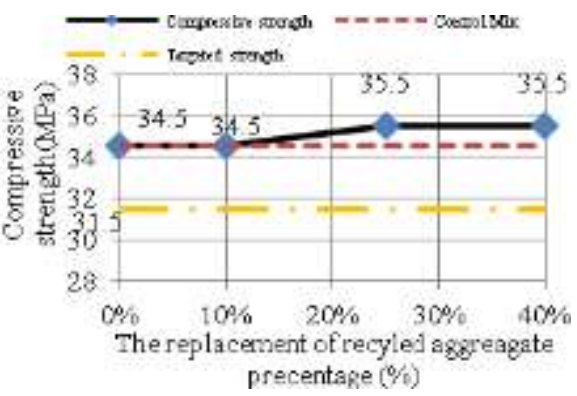

Fig. 6: Compressive resistance of mixes containing recycled aggregate at the age of 28 days.

Crushed bricks have a negative effect on compressive resistance and all the mixes containing the blend of recycled aggregate and crushed bricks had achieved the design compressive resistance at 28 days $25 \mathrm{MPa}$ expect the one 
containing $40 \%$ crushed bricks and the decrease in compressive resistance with increase of crushed bricks is shown in Fig.9.

At the age of 7 days the mix containing $10 \%$ crushed bricks and $40 \%$ recycled aggregate mix had 7\% lower compressive resistance than the control mix and the mix containing $20 \%$ crushed bricks and 30\% recycled aggregate mix had $11 \%$ lower compressive resistance than the control mix A. The 30\% crushed bricks and 20\% recycled aggregate mix had 16\% lower compressive resistance than the control mix and the mix containing $40 \%$ crushed bricks and $10 \%$ recycled aggregate mix had 29\% lower compressive resistance than the control mix A. as shown in Fig.7.

At the age of 14 days the mix containing $10 \%$ crushed bricks and $40 \%$ recycled aggregate mix had $12 \%$ higher compressive resistance than the control mix and the mix containing $20 \%$ crushed bricks and 30\% recycled aggregate mix had 7\% lower compressive resistance than the control mix A. The 30\% crushed bricks and $20 \%$ recycled aggregate mix had $7 \%$ lower compressive resistance than the control mix and the mix containing $40 \%$ crushed bricks and $10 \%$ recycled aggregate mix had $42 \%$ lower compressive resistance than the control mix A. as shown in Fig.8.

At the age of 28 days the mix containing $10 \%$ crushed bricks and $40 \%$ recycled aggregate mix had the same compressive resistance as the control mix and the mix containing $20 \%$ crushed bricks and 30\% recycled aggregate mix had $10 \%$ lower compressive resistance than the control mix A. The 30\% crushed bricks and $20 \%$ recycled aggregate mix had $17 \%$ lower compressive resistance than the control mix and the mix containing $40 \%$ crushed bricks and $10 \%$ recycled aggregate mix had $44 \%$ lower compressive resistance than the control mix A. as shown in Fig.9.

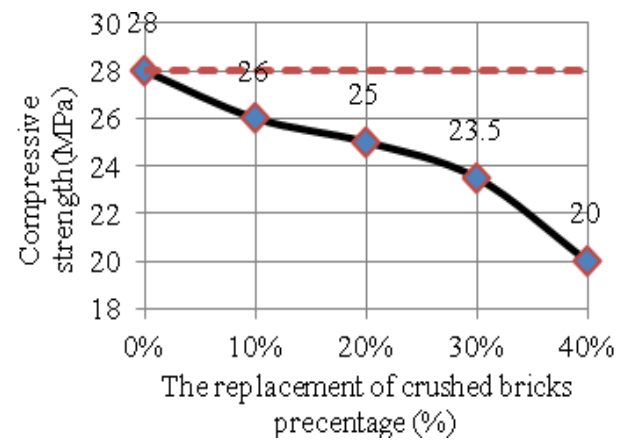

Fig. 7: Compressive resistance of mixes containing crush bricks and recycled aggregate at the age of 7 days.

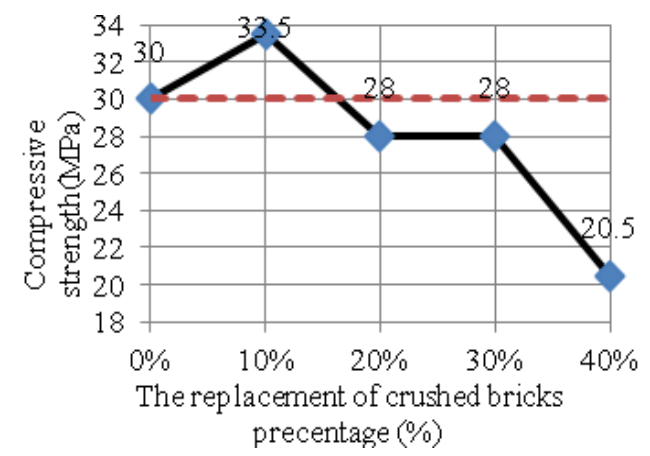

Fig. 8: Compressive resistance of mixes containing crush bricks and

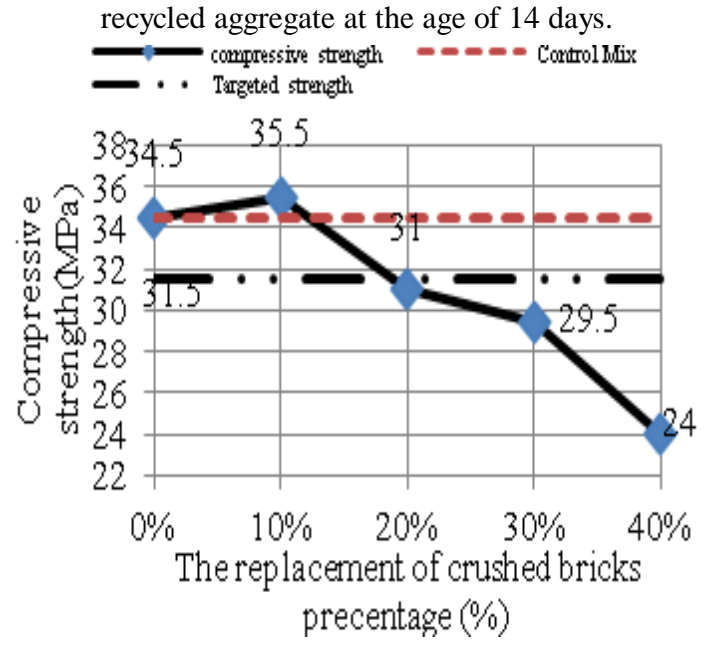

Fig. 9: Compressive resistance of mixes containing crush bricks and recycled aggregate at the age of 28 days.

\section{3) The development of the compressive resistance}

The development of the mixes containing recycled aggregate characteristic compressive resistance at 28 days in the early 7 days vary between (70-79)\% and in 14 days between (79- 86)\% and it's lower than the control mix as shown in Fig. 10.

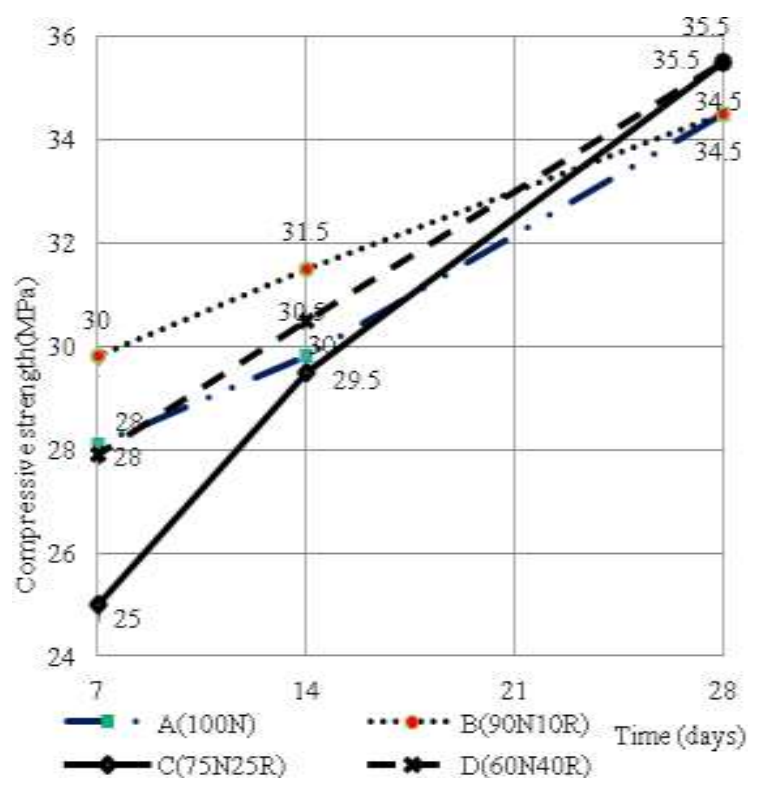

Fig. 10: Development of the compressive resistance of mixes containing recycled aggregate. 
The development of the mixes containing a blend of crush bricks and recycled aggregate characteristic compressive resistance at 28 days in the early 7 days vary between (80- 87)\% and in 14 days between (85-95)\% as shown in Fig. 11.

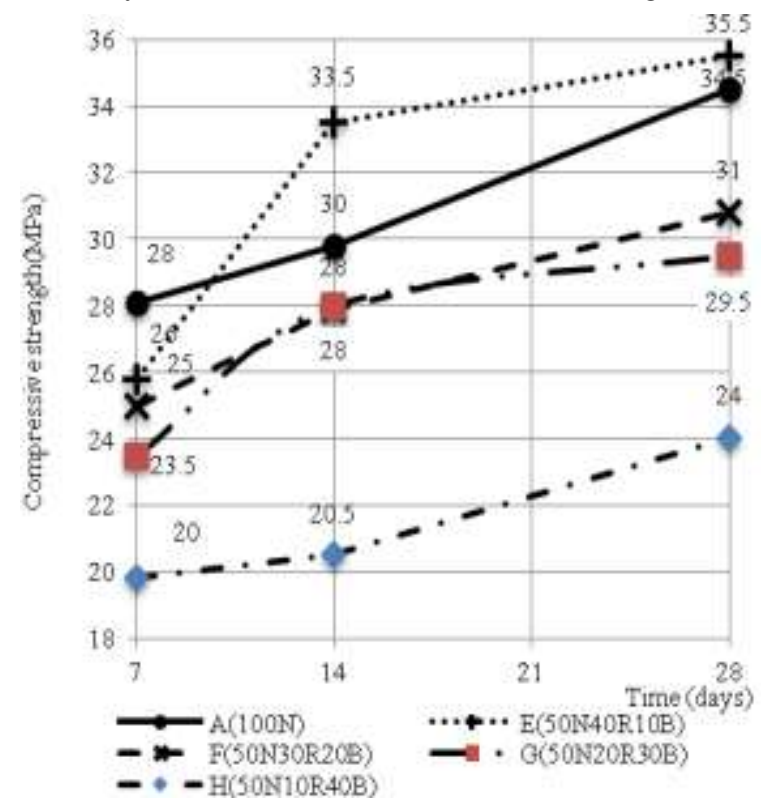

Fig. 11: Development of the compressive resistance of mixes containing a blend of crush bricks and recycled aggregate.

\section{4) Tensile resistance}

Recycled aggregate has positive effect on the tensile resistance with an increase of $23 \%$ when using $10 \%$ recycled aggregate. The mixes containing $25 \%$ and $40 \%$ recycled aggregate had 5\% higher tensile resistance than the control mix as shown in Fig. 12.

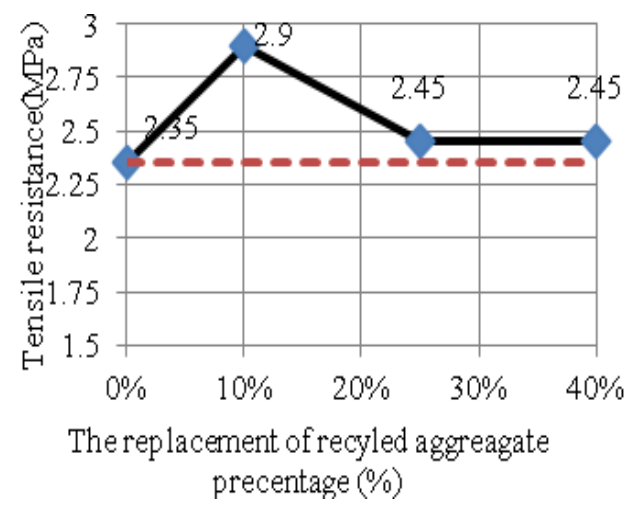

Fig. 12: Tensile resistance of mixes containing recycled aggregate at the age of 28 days.

Crushed bricks have a negative effect on the tensile resistance the mix containing 10\% crushed bricks and $40 \%$ recycled aggregate mix had $23 \%$ lower tensile resistance than the control mix. And the mix containing 20\% crushed bricks and $30 \%$ recycled aggregate mix had $17 \%$ lower compressive resistance than the control mix. The $30 \%$ crushed bricks and $20 \%$ recycled aggregate mix had 17\% lower compressive resistance than the control mix and the mix containing $40 \%$ crushed bricks and $10 \%$ recycled aggregate mix had $13 \%$ lower compressive resistance than the control mix A. as shown in Fig.13.

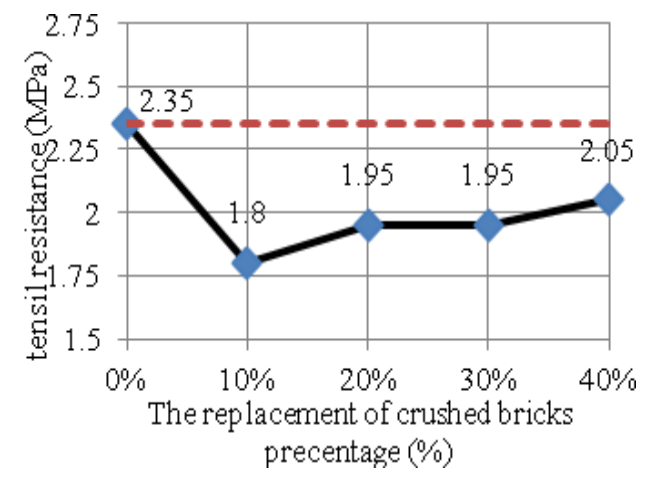

Fig. 13: Tensile resistance of mixes containing crush bricks and recycled aggregate at the age of 28 days.

\section{CONCLUSION}

1. All the slump test results were in the specified range in the mix design which indicates the good workability of the mixes. The mix D containing $40 \%$ recycle aggregate gives a slightly higher workability than the control mix.

2. The crushed brick has a negative effect on the workability decreasing it by $50 \%$ comparing to the control mix when using $40 \%$ crushed bricks.

3. The result shows that the mixes containing recycled aggregate had a compressive resistance in 28 days higher or equal to the compressive resistance of control mix. With $10 \%$ recycled aggregate the compressive resistance was equal to the compressive resistance of control mix and with $25 \%$ and $40 \%$ It had a higher compressive resistance than the control mix by about $1 \mathrm{MPa}$.

4. Crushed bricks have a negative effect on compressive resistance and all the mixes containing the blend of recycled aggregate and crushed bricks had achieved the design compressive resistance at 28 days $25 \mathrm{MPa}$ expect the one containing $40 \%$ crushed bricks and the decrease in compressive resistance with increase of crushed bricks

5. The development of the mixes containing recycled aggregate characteristic compressive resistance at 28 days in the early 7 days vary between (70- 79) \% and in 14 days between (79-86) \% and it's lower than the control mix and the mix had obtain more than $70 \%$ of the 28days characteristic strength in the early 7 days and obtain more than $79 \%$ of the 28 days characteristic strength in the 14 days.

6. Recycled aggregate can be used with partial replacement up to $50 \%$ with little or no effect on the compressive and tensile resistances but the higher than natural water absorption of recycled aggregate need to be taken into account which might affect the workability.

7. Crushed bricks can be used with partial replacement up to $20 \%$ with little or no effect on the compressive and tensile resistances but the higher than natural water absorption of the crushed brick need to be taken into account (pre-wetting) which might affect the workability.

8. The tensile resistance for the mixes containing recycle aggregate was higher by $5 \%$ comparing to the control mix 
and the mixes containing the blend of recycled aggregate and crushed bricks had much lower tensile resistance value.

\section{REFERENCES}

[1] BRE (1998) Recycled aggregates Digest 433. Construction Research Communications, London.

[2] BRE (2000) Quality Control. The production of recycled aggregates. Construction Research Communications, London.

[3] British standards form BS 12 to BS 8110.

[4] Collins, R.J. and Sherwood, P. (1995), The Use of Waste and Recycled Materials as Aggregates; Standards and Specifications. HMSO, London.

[5] Dhir, R.K., Henderson, N.A. and Limbachiya, M.C. (ed.) (1998) Use of Recycled Concrete Aggregate. Thomas Telford, London.

[6] Hansen, T.C. (1986) Recycled aggregate and recycled aggregate concrete Second state of the art report. Developments 1978-1984. RILEM Technical Committee 37 DRC. Materials and Structures 19 (111), 201246. http://dx.doi.org/10.1007/BF02472036

[7] Hansen, T.C. (1992) Recycling of demolished concrete and masonry. RILEM Report No. 6, E \& FN Spon, London.

[8] Lauritzen, E.K. (ed.) (1994) Demolition and reuse of concrete and masonry. Proc. 3rd Int. RILEM Symposium. E \& F N Spon, London.

[9] RILEM TC 121-DRG (1994) Specifications with recycled aggregates. Materials and Structures, 27, 557-559. http://dx.doi.org/10.1007/BF02473217

[10] ECCO (Environmental Council of Concrete Organizations), "Recycling Concrete and Masonry," EV 22, Skokie, Illinois, http://www.ecco.org/pdfs/ev22.pdf, 1999, 12 pages.

[11] Buck, Alan D., "Recycled Concrete as a Source of Aggregate," $A C I$ Journal, American Concrete Institute, Farmington Hills, Michigan, May

[12] 1977, pages 212 to 21

[13] John Newman. 2003. Advanced Concrete Technology,Processes. london : Elsevier Ltd, 2003. ISBN 0750651059.

[14] Mechanical properties of concrete with recycled coarse aggregate. Rahal, Khaldoun. 42 (2007) 407-415, Kuwait: Building and Environment, 2005, Vol. 1.

[15] Mechanical properties, drying shrinkage and resistance to freezing and thawing of concrete using recycled aggregate. Yamato T, Emoto Y, Soeda M. 1998, ACI Special Publication SP 179-7, pp. p. 105-121.

[16] Recycled aggregates Digest 433. London : s.n., 1998, BRE (1998).

[17] Recycled concrete as a source of aggregate. AD, Buck. 1977, ACI Journal, pp. 74(5):212-9.

[18] Recycling of road pavement materials in the Netherlands. Gerardu JJA, Hendriks DF. 1985, Rijkswaterstaat Communications The Hague,.

[19] Strength Behaviour of Recycled Concrete with Partial Replacement of Conventional Aggregate. Md. Siddikur Rahman, Md. Bellal Hossain, Reza Ruksana. 2(2): 80-86, Bangladesh : International Journal of Environment, 2012. ISSN: $2186-0009$.

[20] Variability of recycled concrete aggregate and its effect on concrete properties - a casestudy in Australia. Ravindraraj RS, Steward M, Greco D. 2000, International workshop on recycled concrete.

[21] Waste concrete as aggregate for new concrete. S., Frondistou-Yannas.

a. 1977, ACI Journal, Proceedings, pp. 74(8):373-6. 